\title{
Successful treatment of paramyotonia congenita (Eulenburg): muscle stiffness and weakness prevented by tocainide
}

\author{
K RICKER, A HAASS, R RÜDEL, R BÖHLEN, AND H G MERTENS \\ From the Department of Clinical Neurology, University of Würzburg, and the Department of Physiology I, \\ University of Ulm.
}

SUMMARY Recent studies have shown that the sodium conductance of the sarcolemma is disturbed in paramyotonia. Tocainide is a new antiarrhythmic agent which seems to reduce effectively sodium conductance. Eight patients with paramyotonia were treated with tocainide, whereby the paramyotonic stiffness and weakness brought about by cooling could be prevented.

Paramyotonia congenita is a dominantly inherited disease. The course is non-progressive. ${ }^{1}$ The patients experience an increasing muscle stiffness in a cold environment, especially when muscle effort is involved. Cooling may produce severe weakness which improves only very slowly, often taking several hours. Mainly the hands and face are affected. No effective medication has been described; the patients could only endeavour to keep themselves warm.

More recent studies have led to the supposition that in paramyotonia a dysfunction of the sodium channels of the sarcolemma is present. This is supported by the following observations: when a paramyotonic muscle is cooled from $37^{\circ} \mathrm{C}$ down to $32^{\circ}-30^{\circ} \mathrm{C}$ a dense spontaneous activity of muscle fibre action potentials is registered in the electromyogram. This activity will disappear when the cooling is continued down to about $28^{\circ}-26^{\circ} \mathrm{C}$. The muscle is then paralysed. ${ }^{2}$ In myotonia congenita (Thomsen) no such spontaneous activity is brought about by cooling. Such activity has been recorded, however, in adynamia episodica at the beginning of a hyperkalaemic attack of weakness. ${ }^{3}$

It can therefore be suggested that in paramyotonia the resting membrane potential of the sarcolemma decreases during cooling. This depolarisation of the membrane leads, firstly, to hyperexcitability with spontaneous activity and

Address for reprint requests: Dr $\mathrm{K}$ Ricker, Neurologische Universitätsklinik, Joseph-Schneidẹr-Straße 11, D-8700 Würzburg, Federal Republic of Germany.

Accepted 24 September 1979 then to inexcitability and paralysis. In adynamia episodica Creutzfeld et al, ${ }^{4}$ were able to show depolarisation of the sarcolemma. In paramyotonia intracellular recordings on intercostal muscle fibres of three patients were carried out by Lehmann-Horn et al. ${ }^{5}$ On cooling from $37^{\circ}$ to $27^{\circ} \mathrm{C}$ the resting membrane potential was reduced from $-80 \mathrm{mV}$ to $-40 \mathrm{mV}$. Voltage clamp studies performed by the method described by Adrian and Marshall, ${ }^{6}$ provided strong evidence that cooling increases the sodium conductance in paramyotonia. This increased sodium conductance leads to membrane depolarisation and muscle fibre paralysis. The depolarisation could be completely prevented by adding tetrodotoxin (TTX) to the bathing fluid. It is known that TTX specifically blocks the sodium channel. ${ }^{7}$

It therefore seemed feasible to improve the symptoms of paramyotonia by medication affecting the sodium conductance of the sarcolemma. We used the newly developed antiarrhythmic agent tocainide. Tocainide is a lidocain derivative. It can be given orally and causes only minor side effects. The half-life is significantly longer than that of procainamide. ${ }^{8-11}$

\section{Patients and methods}

We treated eight patients with paramyotonia from four families. Each patient gave his informed consent to examination and treatment. In all families the dominant mode of inheritance was present. All suffered from muscular stiffness and weakness in the cold. No attacks of spon- 
taneous hyperkalaemic weakness were known to any of the four families. All patients showed myotonic runs in the electromyogram at normal muscle temperature, but only the patients of family 3 (table) had clinically recognisable percussion myotonia and active myotonia. Further findings concerned with cases 1,2 , and 8 have already been published. ${ }^{2} 1217$

Over four to six days seven patients were given oral tocainide $400 \mathrm{mg}$ three times a day. One 78-year-old patient (case 2) received tocainide for only one day. Before treatment and four hours after the last dose of tocainide the force of each patient's fist closure was measured under isometric conditions. The patients were asked to make a fist repeatedly 15 times and press the fingers maximally on a metal plate which was connected to the force transducer. The closing and opening of the fingers was also registered mechanographically. ${ }^{2}$ From these recordings the maximal force, the time to threequarters relaxation, and the time to half-way opening of the closed fingers were measured later for each contraction. The temperature was measured in the flexor digitorum communis muscle. The studies were done at a muscular temperature of $37^{\circ}-36^{\circ} \mathrm{C}$ and at $32^{\circ}-31^{\circ} \mathrm{C}$ after cooling the hand and forearm in water. Cooling was carried out within 30 minutes.

\section{Results}

The patients were treated during the cold time of the year. As early as the second day they noticed an improvement in their complaints. When taking walks stiffness in the face and hands no longer occurred. After three to four days work outside in cool weather could be undertaken for longer periods without the hands becoming weak. The effect of medication was most impressive for the patients of family 3. Their considerable muscular stiffness which appeared after cooling even without prolonged muscular effort had completely disappeared. One patient (case 6) was able to eat ice cream for the first time in her life without her tongue stiffening.

The figure shows the complete results in case 1. After cooling down to $31^{\circ} \mathrm{C}$ a distinct weakness was apparent after 15 repetitive maximal contractions. The time to three-quarters relaxation of the muscle was prolonged and the opening of the fingers became slower (paradoxical myotonia). After the 9th contraction the closed fist could no longer be opened. Under medication with tocainide no weakness
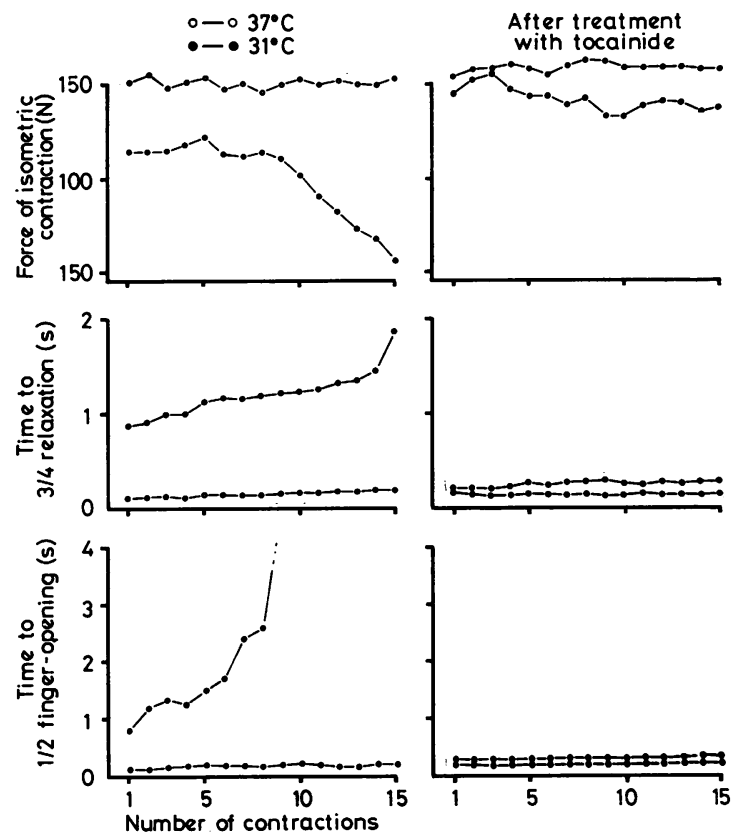

Fig Case 1. This patient was asked to close the fist, carry out a short voluntary maximal contraction, and open the fingers again. This was repeated 15 times. Left: before treatment; recording at $37^{\circ} \mathrm{C}$ intramuscular and after cooling to $31^{\circ} \mathrm{C}$. After cooling progressive muscle weakness is obvious. Relaxation is longer with each contraction, opening of fingers becomes slower. After the 9th contraction fingers can be no longer opened due to stiffness. Right: after treatment with tocainide; following cooling no weakness or slowing occurs.

accurred after cooling. The relaxation of the muscle and the opening of the fingers were no longer impaired.

The table shows the results in the eight treated patients. To allow a better overall view the findings of only the 15 th contraction have been given. In all patients tocainide was shown to have a good effect on weakness as well as stiffness.

The 78-year-old patient (case 2) was treated for only one day since he complained of nausea. His electrocardiogram showed no disturbance. Two patients reported dizziness, anxiety, and tremor on the 2 nd day of treatment; but these complaints disappeared. Five patients had no side effects.

\section{Discussion}

The study has shown that tocainide effectively prevents muscular stiffness and weakness occur- 
ring in paramyotonia congenita with cooling. Since paramyotonia is a lifelong disorder a continuous medication is not to be recommended. Nevertheless, a temporary treatment, for example during winter, will bring some patients relief. A dose of $400 \mathrm{mg}$ tocainide three times daily is adequate. With this dose improvement occurs on the second or third day of treatment. In some cases $400 \mathrm{mg}$ twice a day may be sufficient. Patients without cardiac disease tolerate tocainide very well; however, dizziness, tremor, and anxiety can appear at the beginning of treatment. These initial complaints may be avoided by starting medication with $200 \mathrm{mg}$ three times a day on the first day.

The beneficial effect of tocainide in paramyotonia is surprising. Dengler and Rüdel, ${ }^{8}$ found a good antimyotonic effect in vitro in chemically induced myotonia. However, other antiarrhythmic agents such as procainamide or phenytoin, which bring about a certain improvement in myotonia congenita (Thomsen) showed no effect in paramyotonia. Tocainide apparently works more specifically in paramyotonia than in myotonia congenita (unpublished data). We propose the following explanation: one of the main effects of antiarryhthmic agents is that the sodium conductance of the cell membrane is blocked. This effect seems to be more distinct with tocainide. In myotonia congenita the chloride conductance of the sarcolemma is reduced. ${ }^{13}$ Therefore, drugs which mainly affect the sodium channel have only an indirect influence in myotonia congenita. In some cases of paramyotonia the chloride conductance of the sarcolemma is reduced, whereas in other cases it is not measurably altered. ${ }^{5}$ However, the specific effect of tetrodotoxin already discussed above points to a basic disturbance of the sodium channel in paramyotonia. We must assume that the sodium conductance of the sarcolemma increases by cooling. In this way a progressing membrane depolarisation takes place. The raised intracellular sodium could then interfere with the calcium reuptake into the sarcoplasmic reticulum after a muscular contraction. ${ }^{14}$ This would explain the stiffness. In this hypothesis the normalisation of the increased sodium conductance by tocainide would explain why the stiffness as well as the weakness is prevented by tocainide treatment.

What could be the nature of the defect of the sodium channel in paramyotonia? The voltagedependent changes in the ionic conductances normally are brought about by structural rearrangements within the ion channels. The cause of the abnormal ionic conductance could lie in a change in the steric configuration brought about by a temperature dependent alteration of the large protein molecules which are believed to be ion channels. A minor change of genetic origin in the sequence of aminoacids could lead to such a defect. Another possibility would be a disturbance of fluidity of the sarcolemma due to a genetically caused change in the composition of the membrane phospholipids. This would impair the mobility of the channel proteins which probably must come into contact with one another for certain functions. With the conception of disturbed membrane fluidity a better explanation is given on why the chloride conductance in paramyotonia can apparently be also disturbed in a very variable extent. Kuhn ${ }^{15}$ reported that in dominant myotonia congenita (Thomsen) a change in the composition of fatty acids can be present. Butterfield, ${ }^{16}$ was able to detect a disturbance of the membrane fluidity by electron spin resonance in myotonia congenita. Such studies in paramyotonia are not yet available.

We thank ASTRA Chemicals GmbH, Wedel/ Holstein, FRG, for supplying tocainide.

Table Treatment of eight patients with paramyotonia using tocainide. During each study 15 contractions were carried out, and results are those on the 15th contraction

\begin{tabular}{|c|c|c|c|c|c|c|c|c|c|c|c|c|}
\hline \multirow[t]{2}{*}{ Family } & \multirow{2}{*}{$\begin{array}{l}\text { Case } \\
\text { no }\end{array}$} & \multirow{2}{*}{$\begin{array}{l}\text { Age } \\
\text { and } \\
\text { sex }\end{array}$} & \multicolumn{3}{|c|}{ Force of contraction $(N)$} & \multicolumn{3}{|c|}{ Time to $\$$ relaxation $(s)$} & \multicolumn{4}{|c|}{ Time to $\frac{1}{2}$ finger-opening $(s)$} \\
\hline & & & $37-36^{\circ} \mathrm{C}$ & $32-31^{\circ} \mathrm{C}$ & $\begin{array}{l}\text { Tocainide } \\
32-31^{\circ} \mathrm{C}\end{array}$ & $37-36^{\circ} \mathrm{C}$ & $32-31^{\circ} \mathrm{C}$ & $\begin{array}{l}\text { Tocainide } \\
32-31^{\circ} \mathrm{C}\end{array}$ & $37-36^{\circ} \mathrm{C}$ & $32-31^{\circ} \mathrm{C}$ & $\begin{array}{l}\text { No of } \\
\text { contr.* }\end{array}$ & $\begin{array}{l}\text { Tocainide } \\
32-31^{\circ} \mathrm{C}\end{array}$ \\
\hline $\begin{array}{l}1 \\
2 \\
3\end{array}$ & $\begin{array}{l}\text { F.1 } \\
\text { H.2 } \\
\text { R.3 } \\
\text { L.4 } \\
\text { B.5 } \\
\text { T.6 } \\
\text { J.7 } \\
\text { E.8 }\end{array}$ & $\begin{array}{ll}38 & \mathrm{M} \\
78 & \mathrm{M} \\
25 & \mathrm{M} \\
29 & \mathrm{M} \\
21 & \mathrm{~F} \\
58 & \mathrm{~F} \\
39 & \mathrm{~F} \\
30 & \mathrm{M}\end{array}$ & $\begin{array}{l}156 \\
120 \\
212 \\
205 \\
156 \\
140 \\
132 \\
152\end{array}$ & $\begin{array}{r}58 \\
76 \\
75 \\
721 \\
121 \\
108 \\
64 \\
28 \\
68\end{array}$ & $\begin{array}{r}140 \\
96 \\
215 \\
200 \\
126 \\
136 \\
124 \\
140\end{array}$ & $\begin{array}{l}0.2 \\
0.15 \\
0.14 \\
0.14 \\
0.17 \\
0.11 \\
0.25 \\
0.6\end{array}$ & $\begin{array}{l}1.8 \\
0.5 \\
0.75 \\
0.5 \\
1.1 \\
1.3 \\
0.65 \\
0.85\end{array}$ & $\begin{array}{l}0.3 \\
0.2 \\
0.15 \\
0.18 \\
0.20 \\
0.15 \\
0.16 \\
0.28\end{array}$ & $\begin{array}{l}0.2 \\
0.15 \\
0.18 \\
0.18 \\
0.16 \\
0.18 \\
0.15 \\
0.54\end{array}$ & $\begin{array}{l}12 \\
5.6 \\
6 \\
7 \\
17 \\
2 \\
3.4 \\
6\end{array}$ & $\begin{array}{r}9 \\
15 \\
2 \\
3 \\
1 \\
2 \\
8 \\
4\end{array}$ & $\begin{array}{l}0.3 \\
0.26 \\
0.2 \\
0.18 \\
0.15 \\
0.15 \\
0.18 \\
0.32\end{array}$ \\
\hline
\end{tabular}

* Number of contractions after which the patient could still open the fingers. An opening at the next contraction was no longer possible (compare figure). 


\section{References}

1 Becker PE. Paramyotonia congenita (Eulenburg). Stuttgart: Thieme, 1970.

2 Haass A, Ricker K, Hertel G, Heene R. Influence of temperature on isometric contraction and passive muscular tension in paramyotonia congenita (Eulenburg). J Neurol 1979; 221:151-62.

3 Buchthal F, Engbaek L, Gamstorp J. Paresis and hyperexcitability in adynamia episodica hereditaria. Neurology 1958; 8:347-51.

4 Creutzfeld OA, Abbot BC, Fowler WM, Pearson CM. Muscle membrane potentials in episodic adynamia. Electroencephalogr clin Neurophysiol 1963; 15:508-19.

5 Lehmann-Horn' F, Rüdel R, Dengler R, Lorković H, Haass A, Ricker K. Electrophysiological investigation of paramyotonia congenita. Muscle and Nerve (in press).

- Adrian RH, Marshall MW. Sodium currents in mammalian muscle. J. Physiol (Lond) 1977; 268:223-50.

7 Ritchie JM. Sodium channels and pumps in excitable membranes. In: Membranes and Disease. Bolis L, Hoffman JF, Leaf A, eds. New York: Raven Press, 1976: 351-9.

8 Dengler $R$, Rüdel $R$. Effects of tocainide on normal and myotonic mammalian skeletal muscle. Arznei Forsch 1979; 29:270-3.

9 Winkle RA, Meffin PJ, Fitzgerald JW, Harrison DC. Clinical efficacy and pharmacokinetics of a new orally effective antiarrhythmic, tocainide. Circulation 1976; 54:884-9.
10 Ryan WF, Karliner JS. Effects of tocainide on left ventricular performance at rest and during acute alterations in heart rate and systemic arterial pressure. Br Heart J 1979; 41:175-81.

11 Swedberg K, Pehrson J, Rydén L. Electrocardiographic and hemodynamic effects of tocainide. Eur J Clin Pharmacol 1979; 14:15-9.

12 Ricker K, Hertel G, Langscheid K, Stodieck S. Myotonia not aggravated by cooling. Force and relaxation of the adductor pollicis in normal subjects and in myotonia as compared to paramyotonia. J Neurol 1977; 216:9-20.

13 Lipicky RJ, Bryant SH. A biophysical study of the human myotonias. In: Desmedt JE, ed. New developments in electromyography and clinical neurophysiology. Vol. 1. Basel: Karger, 1973; 451-63.

14 Lee KS, Klaus W. The subcellular basis for the mechanism of inotrophic action of cardiac glycosides. Pharmacol Rev 1971; 23:193-261.

15 Kuhn E. Myotonia. In: Desmedt JE, ed. New developments in electromyography and clinical neurophysiology. Vol 1. Basel: Karger, 1973: 413-9.

16 Butterfield DA. Spin label study of erythrocyte membrane fluidity in myotonic and Duchenne muscular dystrophy and congenital myotonia. Nature 1976; 263:159-61.

17 Haass A, Ricker K, Rüdel R, Lehmann-Horn F, Böhlen R. Paramyotonia and Myotonia: mechanical and electromyographical parameters related to abnormal membrane conductances. Muscle and Nerve (in press). 